\title{
Editorial
}

\section{THE MEDICAL STUDENT AND LEPROSY}

Those who are committed to attempting to control leprosy with the means currently available are in little doubt that case-finding and chemotherapy are of fundamental importance. Despite the exciting advances which are being made towards the development of a vaccine and to procedures which may permanently improve the immune status of patients with lepromatous leprosy, recent publications from the World Health Organisation ${ }^{1,2}$ have underlined the continuing need to find and diagnose as many cases as possible and to treat them with multiple drug regimens.

Since the WHO publication on such regimens in 1982, virtually all leprosyendemic countries have implemented, or are in the process of implementing, multiple drug therapy, but in a recent Report from WHO of a consultation on the implementation of multiple drug therapy (MDT) for leprosy control ${ }^{3}$ it is disconcerting to read that " . . this has in general been on a limited scale and there is an imperative need to hasten and expand the pace of implementation of the revised strategy.' This comment could appropriately be linked and considered with the fact that only 5.3 million cases of leprosy are actually registered worldwide ${ }^{4}$ leaving at least that number-possibly more - who are estimated to have the disease, but have been neither detected nor offered treatment. The 1985 WHO Report on MDT referred to above goes on to consider some of the practical problems which have been revealed in different countries in implementation and draws attention to the shortage of qualified staff as one of the main constraints. Yet this problem is far from new; it was recognized repeatedly during the era of dapsone monotherapy and its increasing importance was predicted by experienced leprologists all over the world when MDT was first discussed, some even expressing the view that safe implementation would prove impossible, or dangerous, if urgent attention could not be given to the upgrading of health personnel concerned in the diagnosis, classification, treatment, management and follow-up of patients with this disease. These views have been upheld in countless meetings, discussions, ad hoc working groups and resolutions of the International Federation of Anti-Leprosy Associations (ILEP) whose member organizations are responsible, directly or indirectly, for a considerable percentage of the total of 
registered leprosy patients. Furthermore defects in the total numbers of people available for leprosy control, or their quality, or both, are plain to see for anyone who travels regularly in most leprosy-endemic countries, where it is also apparent that there is a lack of motivation, supervision, enthusiasm and 'drive' from people at the top.

Why are these defects still with us in 1986? Does the fault lie with Ministers or Ministries of Health? Health planners? Schools of training? ILEP or WHO? Should the non-government organizations have given greater emphasis to the training of personnel for leprosy control, when they began to realize, as they did some years ago, that the total of known, registered cases under their care was not rising satisfactorily? There is almost certainly no simple answer, but one possibility which has attracted attention in recent years centres on the observation that in leprosy (perhaps more than in other diseases) it is medically qualified doctors who exert enormous influence, not only on health planning and policy, but also, perhaps more importantly, on the attitude of the medical and lay community to leprosy patients and to the whole matter of leprosy control. Any leprologist of experience can testify to the disastrous effect of a locally qualified doctor, posted to take charge of a district hospital, who turns out to know nothing about leprosy and to be manifestly af raid of touching a patient. Postgraduate or 'continuing' education is of course greatly to be commended, if only as a means of keeping qualified doctors up to date with advances or changes in aspects of leprosy, such as chemotherapy, and those who have made systematic efforts to contact general practitioners in leprosy-endemic areas, as for instance in Bombay, ${ }^{5}$ have already observed improvement in standards of case-detection and treatment. But we have to remember that many doctors become extremely busy almost from the moment of qualification; they scatter to different parts of the country and of ten have to earn money in order to repay debts incurred during their training. To some extent, their ideas about many diseases, including leprosy, are already formed. But behind every new doctor there is a medical student and it is the purpose of this editorial to suggest that we have, in the thousands of students who are constantly passing through medical schools in all leprosyendemic countries of the world, a vast and important 'captive audience'. Their basic training in leprosy, including the formation of positive attitudes to the disease and clinical contact with patients, can surely no longer be ignored.

Looking only at those pages relating to leprosy-endemic countries, a glance at the World Directory of Medical Schools ${ }^{6}$ shows only too clearly how difficult it would be to get to grips with the input of leprosy in the curriculum of universities in so many different countries. It must however be recorded that in some centres impressive advances in the teaching of leprosy to medical students have already been made. In a previous communication to this journal, ${ }^{7}$ Warndorff drew attention to the contribution made by the All-Africa Leprosy and Rehabilitation Training Centre (ALERT) to the training of medical students from the medical faculty in Addis Ababa, over a period of many years, and Ganapati, ${ }^{5}$ working 
mainly in the slums of Bombay, has described the active involvement of medical schools, including teaching staff and students in the leprosy programme. Furthermore, we have recently received an account ${ }^{8}$ of a potentially very important 'Leprosy Teaching Module' which is in use at the University of Calabar, Cross River State, Nigeria. At the beginning of their final year of study, students spend $3 \frac{1}{2}$ months working in the field in community health and the leprosy component is linked to primary health care. The final year examinations include compulsory questions on leprosy. Such initiatives, together with those which have already been taken in various other parts of India, indicate what can be accomplished with a certain amount of determination and planning. This makes it all the more deplorable to record that, in contrast to these excellent examples, the general situation with regard to the teaching of this subject to medical students is far from satisfactory.

Ironically, where the leprosy problem is most severe, it is often the fact that it is virtually neglected in the medical student curriculum. Some years ago, in a letter to the International Journal of Leprosy, ${ }^{9}$ attention was drawn to the totally inadequate amount of time allocated to this subject in many medical schools and it is still the case that an adequate, regular, teaching-learning module, including clinical experience, has not been established in most schools where leprosy is endemic. It would, however, be wrong to imply that this has not been recognized in the past by WHO, ILEP and various other agencies, who have attempted to draft recommendations for a suitable module. In fact a Workshop on the training of undergraduate medical students in leprosy, sponsored by the Gandhi Memorial Leprosy Foundation and the Medical Council of India, was held in Calcutta in February 1979, and a detailed syllabus was described in a (restricted) WHO document later that year, covering activities and studies in clinical medicine, pathology, microbiology, pharmacology, surgery, preventive and social medicine. In 1980 a symposium was held at the MKCG Medical College, Berhmapur, Orissa on 'Intensification of Teaching of Leprosy to Medical Undergraduates, ${ }^{10}$ again giving a fairly detailed account of the main training required. The importance of the medical student in leprosy was further emphasized in Report of Task Force ' $D$ ' on mass communications, health education and people's participation. ${ }^{11}$

But the truth is that neither in India, nor elsewhere, have such recommendations been generally accepted and applied, possibly because of the inherent difficulty of making recommendations for schools in so many different parts of the world, with varied resources. Foremost amongst these are the human resources in terms of teachers, motivators, specialists in various subjects who can, at least in theory, be either nominated or called upon to assist. But the plain truth of the matter is that enthusiastic teachers with a basic knowledge of leprosy (and an interest in the subject) simply do not exist and it may be unhelpful to continue stating that they 'should be identified'. However, in another recent publication from $\mathrm{WHO},{ }^{12}$ the basic, practical steps to be taken in order to provide 
' ... teachers competent to assist the students to reach their objectives' have now been outlined by authors with long experience in this field and one wonders if this is perhaps the moment to consider a meeting of representatives of WHO, ILEP, ministries of health and other agencies interested in leprosy control, to discuss the medical student and leprosy? In this context it may be helpful to keep in mind that most medical students are more than accustomed to self-instruction and that the potential of distance-learning techniques ${ }^{13}$ is very considerable. It could also be valuable to establish appropriate health-learning materials, including transparencies, video tapes and a full range of written material, in appropriate sections of teaching 'laboratories' or demonstration centres in the medical school.

Medical students are often hard-working, interested and receptive people. Experience shows that, if given the chance, they will write essays on leprosy subjects, go to work in leprosy hospitals and control projects, assist in research and support voluntary agencies. It would not cost much money to radically upgrade their involvement with leprosy at the undergraduate stage. Is there not a case for improving our approach to such potentially valuable members of the profession?

Department of Dermatology,

A C McDougall, Editor

The Slade Hospital,

Headington,

Oxford $O X 37 \mathrm{JH}$

\section{References}

1 WHO. Chemotherapy of leprosy for control programmes. Report of a WHO Study Group. Technical Report Series 675. World Health Organisation, Geneva, 1982.

2 WHO. Epidemiology of leprosy in relation to control. Report of a WHO Study Group. Technical Report Series 716. World Health Organisation, Geneva, 1985.

${ }^{3}$ WHO. Report of a consultation on implementation of multidrug therapy for leprosy control. WHO/LEP/851. World Health Organisation, Geneva, 1985.

${ }^{4}$ WHO. Report of a meeting on action plans for leprosy control. New Delhi, 23-25 August 1982 (Unpublished WHO document WHO/LEP/83.1 Corr 1).

${ }^{5}$ Ganapati R. Personal communication 1985.

${ }^{6}$ WHO. World Directory of Medical Schools, World Health Organisation, Geneva, 1979.

7 Warndorff JA. Training in leprosy of medical students in Ethiopia. Letters to the Editor. Lepr Rev, 1981; 52: 284-5.

8 Brightmer MI. Personal communication, 1986.

9 McDougall AC, Weddell AGM. The Teaching of Leprosy in Medical Schools: Four and OneHalf Hours in Three Years. Correspondence. Int J Lepr, 1980; 48: 329

${ }^{10}$ Intensification of Teaching of Leprosy to Medical Undergraduates. Report of a Symposium at MKCG Medical College, Berhampur, India, 1980.

11 Mass Communications, Health Education and People's Participation. Report of Task Force 'D' Convenor R.H. Thangaraj. Working Group, Goverment of India, 1981.

12 WHO. Training in leprosy. WHO document WHO/CDS/LEP/86.2. World Health Organisation, Geneva, 1986.

${ }_{13}$ Morley D, Savage-King F. Appropriate teaching aids. Br Med J, 1984; 289: 1057-8. 